\title{
Vote Probabilities, Thresholds and Actor Preferences: Decision Capacity and the Council of the European Union
}

\author{
Madeleine O. Hosli ${ }^{1,2} \cdot$ Běla Plechanovová $^{3} \cdot$ Serguei Kaniovski $^{4}$
}

Received: 2 August 2017 / Accepted: 16 April 2018 / Published online: 30 May 2018 (C) The Author(s) 2018

\begin{abstract}
This paper studies how voting rules affect the ease with which decisions are made, basing the analysis on the key premise that ideology makes some coalitions more likely to form than others. Our study focuses on the Council of the European Union (EU), where member states hold different voting weights and ideological positions are strongly linked to the affiliation of actors to political parties. Accordingly, to explore the influence of ideology on the probability of coalition formation, and to thus formulate a 'decision probability', we incorporate ideological positions in the analysis of efficiency of the voting system. For the case of the EU, we particularly consider the transition from the triple-majority voting system of the Nice Treaty to the double-majority system incorporated into the Lisbon Treaty. The standard assumption that member states vote independently and affirmatively with a probability of 0.5 leads to a more pessimistic view of the Council's decisionmaking capacity than does the premise that member state votes are biased towards voting with the Council majority. The latter assumption is supported by voting data and anecdotal evidence on the 'consensus-seeking' culture in the Council. Hence,
\end{abstract}

Madeleine O. Hosli

hosli@fsw.leidenuniv.nl

Běla Plechanovová

bela.plechanovova@fsv.cuni.cz

Serguei Kaniovski

serguei.kaniovski@wifo.ac.at

1 Research Group Diplomacy and Global Affairs, ISGA, Faculty of Governance and Global Affairs, Leiden University, Turfmarkt 99, 2511 DP The Hague, The Netherlands

2 UNU-CRIS, Brugge, Belgium

3 Charles University, Prague, Czech Republic

4 Austrian Institute of Economic Research (WIFO), Vienna, Austria 
this paper offers some insights into the 'efficiency' of the decision-making process, given institutional voting rules, in combination with actual actor ideological positions.

Keywords Council of the EU · Nice Treaty $\cdot$ Lisbon Treaty $\cdot$ Power to act · Probability of coalition formation

\section{JEL Classification $\quad \mathrm{C} 71 \cdot \mathrm{D} 72$}

\section{Introduction}

How does the choice of decision rules affect the 'capacity to act' of an institution? How strong is the status quo bias inherent in different voting rules? The majority of studies on decision-making processes in the EU focus on the relative influence of actors and institutions in the EU's inter-institutional setup, either basing the analysis on cooperative game theory and notably voting power analysis, or using extensive form games combined with spatial voting analysis (or a combination of these approaches). ${ }^{1}$ This paper studies effects of voting rules in the Council of the EU over time and aims to explore how the theoretical probability that 'winning coalitions' form in this institution is affected by knowledge on actor's ideological positions. Hence, the size of the institution, changes in voting rules and (empirical) information on the position of Council actors in terms of locations on important policy dimensions are assumed to determine the ease with which decisions can be taken in practice and hence, the extent of the institution's status quo bias.

The standard approach to measuring the efficiency of a voting body is to compute the probability of it passing a motion. This probability indicates the ability of the voting body to act, or the extent of status quo bias. While the probability of passing a motion depends on the voting behavior as well as voting rules, the standard approach focuses exclusively on the role of voting rules. Accordingly, the standard tool for measuring the efficiency of a voting body is the 1971 Coleman measure on the power of a collectivity to act. Defined as the ratio of the number of winning coalitions to the total number of all conceivable coalitions, the Coleman measure equals the probability of a decision in favor of a change in the status quo, provided that all coalitions are equally probable. ${ }^{2}$ This assumption is equivalent to the binomial model of voting in which each vote has an equal probability of being for or against

\footnotetext{
1 See, for example, Tsebelis (1994, 1995), Steunenberg (1994), Crombez (1996), Garrett and Tsebelis (1996, 1999), Moser (1996, 1997), Laruelle (1997), Hubschmid and Moser (1997), Thomson and Hosli (2006), and Napel and Widgrén (2006).

2 By 'coalition' we mean the set of members voting affirmatively, i.e. against the status quo, in accordance with standard terminology in the literature on voting power and voting procedures (Felsenthal and Machover 1998).
} 
a motion and all votes are independent; also known as the 'Independent Coalition Culture' (ICC). The binomial model is a rational starting point in the absence of prior information on the member states' preferences concerning the ballot issues. It is the benchmark model used in constitutional design (Felsenthal and Machover 2004).

The critics of the power measurement argue that the standard analysis ignores the preferences of voters. ${ }^{3}$ The relative ease of making decisions will, without any doubt, depend on the distribution of preferences among the relevant actors. Selck (2005) uses this point to explain the relative lack of inertia in Council decisionmaking. According to Selck, a clear desire to overcome the status quo exists in EU decision-making, which explains why decisions are still being made despite the previously discussed institutional inertia. In other words, preference homogeneity exists among EU decision makers. But there are other reasons for a possible inherent theoretical status quo bias in Council decision-making. First, recent EU enlargements have likely increased the heterogeneity of preferences among the member states in the Council while decreasing the pace of decision-making. Second, the possibility of a bloc by a coalition comprising only four member states (under the current Lisbon voting rules) might hamper more important changes that truly alter the status $q u o$, while at the same time preference homogeneity on a host of smaller, technical issues might create a false sense of progress.

An empirically informed analysis of voting in the Council is hampered by the fact that most decisions are reached 'behind closed doors'. Since 1993, transparency has somewhat increased through the publication of voting records. ${ }^{4}$ The relative frequency of 'yes' and 'no' votes in this data refutes the assumption of equally probable voting outcomes and therefore challenges the binomial model of equally probable and independent votes. Voting data reveals that divisions typically occur with very different frequencies, and that votes of the member states are highly positively correlated. In sum, there is a strong case for a 'culture of consensus' in the Council (Hix 1999, Sherrington 2000, Hayes-Renshaw et al. 2006, Hosli 2007). Dissenting votes, as well as abstentions, seem to serve the purpose of scoring points 'at home', i.e. demonstrating opposition as a strategy in domestic politics. This also implies that, in practice, member states are biased towards voting 'yes' in the Council.

Unlike voting rules, which are formally provided for in the treaties of the EU, the future motions and how divided over them the Council will be cannot be foreseen. Our point of departure is the assumption that ideological factors make some coalitions more likely than others regardless of the actual issue at stake, and that some issues are more controversial than others. We propose to model the underlying common tendencies among groups (blocs) of member states using the correlation between their votes as the simplest and most widely used measure of stochastic dependence. In this model,

\footnotetext{
3 See Napel and Widgrén (2004) and the critique in Braham and Holler (2005a), as well as the reply in Napel and Widgrén (2005) and the rejoinder in Braham and Holler (2005b).

4 See Daniel Naurin's web page of Council voting data, available at http://www.councildata.cergu.gu. $\mathrm{se} /$.
} 
1. the degree of acceptance of an issue by a single member state is captured using the marginal probability of an affirmative vote, and

2. the correlation matrix between the affirmative votes reflects commonalities in the preference of the member states that exist regardless of the actual issue on ballot.

The standard binomial model of voting assumes a marginal probability of 0.5 and zero correlations. In the standard model each state flips a fair coin, and all such flips are independent of each other. In our model, by comparison, each member state flips a 'biased coin', where the bias may depend on the issue on ballot, and all such flips are correlated according to the ideological positions of the member states.

In the past two decades the EU has experienced dramatic changes, the most salient being its increase in membership from fifteen to twenty-eight member states. Clearly, enlarged membership increases the risk of 'deadlock' in the Council. ${ }^{5}$ Not only does the unanimity rule increase a committee's status quo bias as membership grows by introducing more 'veto players', ${ }^{6}$ but a similar effect materialized in the framework of the Nice triple-majority rule and may, although to a lesser extent, be inherent in the more recent double-majority clause introduced by the Lisbon Treaty. Hence, if member state voting moves towards a probability of voting 'yes' of one half, and if the current percentage of the vote total needed to reach decisions in the Council is not lowered, the recent enlargements are indeed likely to lead to an increase in the EU's propensity to revert to the status quo. We show however, that if EU member states continue to adhere to the 'consensus culture' in the Council, the status quo bias will decrease significantly and in practice, 'decision-making efficiency' will be higher than the 'raw' assessments of decision efficiency, based on voting rules and the ICC assumption, suggest.

This paper offers an in-depth discussion of the evolution of voting rules in the Council, combining the insights from the contemporary political science research on the functioning of the Council with theory of power measurement. Power computations provided in the paper illustrate how different assumptions about the level of consensus among the member states influence the probability of a collective decision. The degree of consensus among the member states can be modeled using the probability of acceptance, or using the correlations between the votes. The correlation matrix offers a particularly flexible way of accounting for heterogeneity among the member states that is driven, for example, by ideological differences, or by the realities of their countries. We discuss both modeling approaches to modeling the degree of consensus.

The next section describes how the present paper approaches the problem of assessing voting efficiency, or the inherent status quo bias of an institution. The definition of voting blocs and the construction of the corresponding correlation matrices are discussed in Sect. 3. Section 4 applies this analysis to the Council of the EU and Sect. 5 summarizes our results and conclusions.

\footnotetext{
5 For an early analysis of this issue, see König and Bräuninger (1997, 1998).

6 See, for example, Tsebelis (1995).
} 


\section{Winning Coalitions and the Analysis of Decision Efficiency}

Even before the introduction of the Nice Treaty voting rules on November 1st, 2004, most authors found the EU's capacity to act to be rather limited. In a spatial analysis of EU decision-making, Crombez (1996) found that certain institutional elements fostered 'indecision' in the EU and proposed adopting the simple majority rule in the Council to alleviate this inherent inflexibility in the EU's procedures. Similarly, resorting to simple majority had been advocated early on by Lane and Maeland (1995) and by Peters (1996). The issue of status quo bias has also been addressed in studies using more empirical materials. Golub (1998) and König and Bräuninger (1998), for example, both analyzed the 'swiftness' of decision-making in the history of the EU. Golub found, contra conceived wisdom, that the quickness of decision-making was quite reasonable in the early EU-for which 'Eurosclerosis' is usually diagnosed-compared to the 1980s and 1990s, and that it had not slowed down after the 1995 enlargement (Golub 2002). By contrast, König and Bräuninger (1998) found that the pace of decision-making appeared to be slowing down over time, not least since the European Parliament's leverage increased. This finding was supported in Schulz and König (2000) and by König and Bräuninger (2002). Sloot and Verschuren (1990), an earlier study in this tradition, found that the introduction of the cooperation procedure in the mid-1980s with the ratification of the Single European Act (SEA) had a positive effect on the swiftness of decision-making by increasing the use of qualified majority voting (QMV) instead of unanimity in the Council. Hence, the general thrust of these studies suggests that QMV has facilitated decision-making in the EU.

Matters have obviously been complicated by the decision-making rules incorporated in the Nice Treaty of December 2000, and the subsequent accession of twelve new members. Baldwin and Widgrén (2004) provided evidence of the Council's declined ability to act as a result. They pointed out that the rules provided in the Nice Treaty are "so flawed that EU leaders asked to reform them before they were even implemented" (p. 7). A study by Leech (2002) concurrently found that the high decision-making thresholds (both before and after the Treaty of Nice) have rendered EU decision-making decidedly rigid. Empirical studies nonetheless claim that the general pace of decision-making in the Council has not significantly decreased, even after the 2004 enlargement (Golub 2007; Hagemann and De Clerck-Sachsse 2007).

To assess the EU Council's inherent 'efficiency' of decision-making, or the extent of status quo bias, we model the probability of the occurrence of winning coalitions. Traditionally, this approach assumes the binomial model of voting, implying that each coalition is equally likely to form. ${ }^{7}$ As the assumptions of the binomial model do not hold, Coleman's original measure-defined as the ratio of winning coalitions in the total number of conceivable coalitions-cannot accurately reflect

\footnotetext{
7 This approach has been used, for example, by Buchanan and Tullock (1962), Coleman (1971, 1973), Kilgour and Levesque (1984), Peters (1996b), König and Bräuninger (1997, 1998, 2002), Baldwin et al. (2001), Leech (2002), Baldwin and Widgrén (2004), Hosli and Machover (2004), and Plechanovová (2004).
} 
the probability of a decision being reached in practice whereas it of course is still correct in an ex ante, constitutional perspective. To account for the similarity of members' preferences, or the strength of the consensus-seeking culture within the Council, we need to change the underlying probabilistic assumptions.

Such a change is feasible because the Coleman measure is a compound measure that takes into account the calculus of coalitions implied in the formal voting rules, as well as the likelihood of their occurrence. Coalitions that are winning under equally probable and independent votes continue to win when the votes lose either property, what changes, however, are the probabilities of their occurrence. This fact is important because it allows the properties of the voting rule to be studied separately from those of the probability model. Changing the voting rules by assigning different weights to the members of a voting body, or changing the decision quota, will likely alter the set of winning coalitions, but not the probability distribution on the set of all coalitions.

In the simplest case, a voting rule in a weighted voting game is given by the number of votes each member of the voting body commands and the fraction of the total number of votes required to pass a motion. The voting rules of the EU, however, are more complex. The set of winning coalitions under complex voting rules such as the triple-majority rule introduced by the Nice Treaty, or the double-majority rule with a blocking minority requirement of the Lisbon Treaty, can only be evaluated by directly testing each conceivable configuration of votes. This is because the so defined voting game is not a 'weighted voting game' according to the standard definition used in cooperative game theory (Felsenthal and Machover 1998, ch. 2). Using the language of Boolean functions, the binary function jointly defined by the voting rules is not a linear threshold function (Crama and Hammer 2011, ch. 9). This leads direct enumeration to be the only feasible way of certifying which coalitions are winning and which ones are losing. The computational study by Kurz and Napel (2016) shows that dimension of the Lisbon voting system is at least seven, i.e. a combination of at least seven weighted voting games is needed to obtain the set of winning coalitions under the Lisbon voting system.

The modeling approach described above has been proposed and developed in Kaniovski (2008) and Kaniovski and Das (2015). It allows calibrating an accurate model of the voting body given one's prior beliefs about the preferences of the members and the degree of commonality or rivalry among them. Expressed in terms of the correlation coefficients, these beliefs can be used to forecast the probabilities of different voting outcomes, and hence the probability of a voting body as a whole passing a motion. This probability then reflects the power of a collectivity to act, or the efficiency of the voting body - in our case, the Council of the EU.

Computing the above-mentioned probability requires a joint probability distribution on the set of voting outcomes. Individual probabilities of an affirmative vote and second-order correlation coefficients between pairs of such votes do not uniquely define a joint probability distribution. Bahadur (1961) has provided a general solution to the aggregation problem of finding a joint probability distribution with given marginal probabilities and correlation coefficients in terms of higher-order correlation coefficients. The difficulty in applying his result, however, lies in the excessively large number of required parameters. 
Regularization offers a practical solution to the aggregation problem. It imposes additional criteria on the solution for it to have certain properties; in our case this is uniqueness. We use 'constrained quadratic optimization' to find a particular solution, i.e. a joint probability distribution satisfying given marginal probabilities of affirmative votes and a given correlation matrix between them. This particular solution is closest, in the sense of having the smallest sum of squared deviations, to the joint probability distribution in the baseline case of independent votes. Solving the most general optimization problem - with arbitrary marginal probabilities and second-order correlation coefficients-requires numerical optimization.

Calibrating the model for 27 EU member states would require at least 352 parameters to generate a joint probability distribution over the $134,217,728$ conceivable voting outcomes, or coalitions. With the current 28 member states, by comparison, the number of coalitions in fact doubles, and the minimal number of parameters increases to 379 . To reduce this computational complexity, we are grouping the member states into homogenous voting blocs, comparable to the approach used by Kirman and Widgrén (1995). The efficiency calculations are then performed using the voting blocs rather than individual member states, although a voting bloc may comprise a single state. This is no ideal way of 'clustering' member states into blocs, but given the circumstances, it is the most reasonable way to go about. EU member states are very likely to be influenced in their voting behavior by the political party affiliation of their highest ranked government officials. The number and composition of the voting blocs in our study will hence be determined by 'Ideological Scores' (see below). The voting weight of a voting bloc then simply is the sum of the votes its members command.

\section{Actor Preferences and Alignments in the Council of the EU}

Given the strong influence of party politics on the structure of the EU political space, notably due to the strengthening of the role of the European Parliament (EP) over time, it can be assumed that the political location of an actor's party matters in decision-making. That applies also to a primarily intergovernmental institution such as the Council of the EU. Recent institutional changes have more explicitly connected results of the EP elections to the political profile of the European Commission and with this, contribute to politicization of the EU's legislative process. The Council, the ultimate decision-maker on EU legislation, is inevitably part of this process, as was established already a while ago (Hagemann and Høyland 2008), even more so with the broadening scope of the co-decision procedure and qualified majority voting introduced by the Lisbon Treaty. The changes to the decision-making rule for the Council, officially applicable since November 2014, may also further this trend.

Therefore, to identify the most probable groups that may have a potential to form coalitions within the Council of the EU, we use data on positions of the party groups in the EP, based on a survey carried out in 2010 (McElroy and Benoit 2012). The EP party groups overarch the broad spectrum of national political parties that form the governments in EU member states, while at the same time have the potential 
to facilitate the coordination of actions of those involved in the legislative process across the EU's institutions. We do not claim this is always the case, but since most EU legislation requires approval of the EP and we see a high coherence of party groups' voting in the EP (Hix and Høyland 2013), using the party family affiliation for EU governments seems a sensible approach to take.

We believe that, in the long run, the overall position of the government of an EU member state may be defined by the affiliation of the Prime Minister of this government to the respective EP party group. Most EU states, however, have coalition governments and therefore the Prime Minister and the minister responsible for a particular policy area may be affiliated with different political parties. We hence assume that should they disagree on individual pieces of legislation, the position of the Prime Minister will usually prevail or that the position will be within the interval of 'tolerance' of the party leading the coalition - that is, the positions that the leading party will still accept. We are aware this assumption is somewhat arbitrary, but we believe that its foundation is sound. First, results of the empirical research on coalition formation in the Council of the EU does not provide any alternative clear-cut pattern that would describe long-term coalition behavior of the members of the Council of the EU based on distinct substantive preferences. The patterns identified in the literature, e.g. North-South (e.g. Mattila 2004) or North-South-East (Naurin and Lindahl 2008) or core-periphery (Plechanovová 2011) or a rich-poor divide (Bailer et al. 2015) point either to closeness of the political culture or to the behavioral pattern under given power constellations of the members in the Council. Second, following the previous argument, final decisions in the EU Council remain highly consensual, indicating that the tendency towards the highest possible support of the EU legislation persists. Given the broader context of the legislative process in the interaction with the European Commission and the European Parliament, both institutions with a clear political profile, the assumption of the political party leading the member state's government providing the political identity of the member of the Council as an actor seems fully consistent with the hypothesis of the correlated votes we are using for our analysis.

Consequently, we take the average positions of the EP party groups with which the Prime Ministers of member states were affiliated during the last legislative term, from mid-2009 to mid-2014. The mean values are taken on two dimensions. The first dimension is the traditional ideological left-right positioning, reflecting the general attitude of an actor to socio-economic policies in relation to other actors in a comparative perspective (Benoit and Laver 2006). The second dimension is an actor's attitude as to whether the EU should develop into a 'federation' or stay a 'Europe of nation-states'. Both dimensions are assessed on a scale ranging from 0 to 20 (see Fig. 1). The distributions of the party groups' positions along the left-right spectrum and the future integration dimension however, follow diverse trajectories. ${ }^{8}$ Given the fact that during the EP's last legislative term

\footnotetext{
${ }^{8}$ On the relation of the left-right positioning and support for EU integration dimensions, notably see Hooghe et al. (2002).
} 


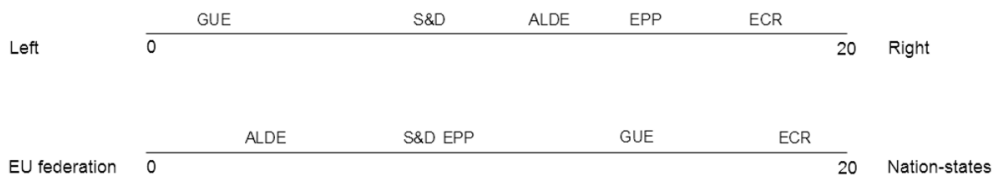

Fig. 1 Positions of party groups on the left-right and federalization dimensions

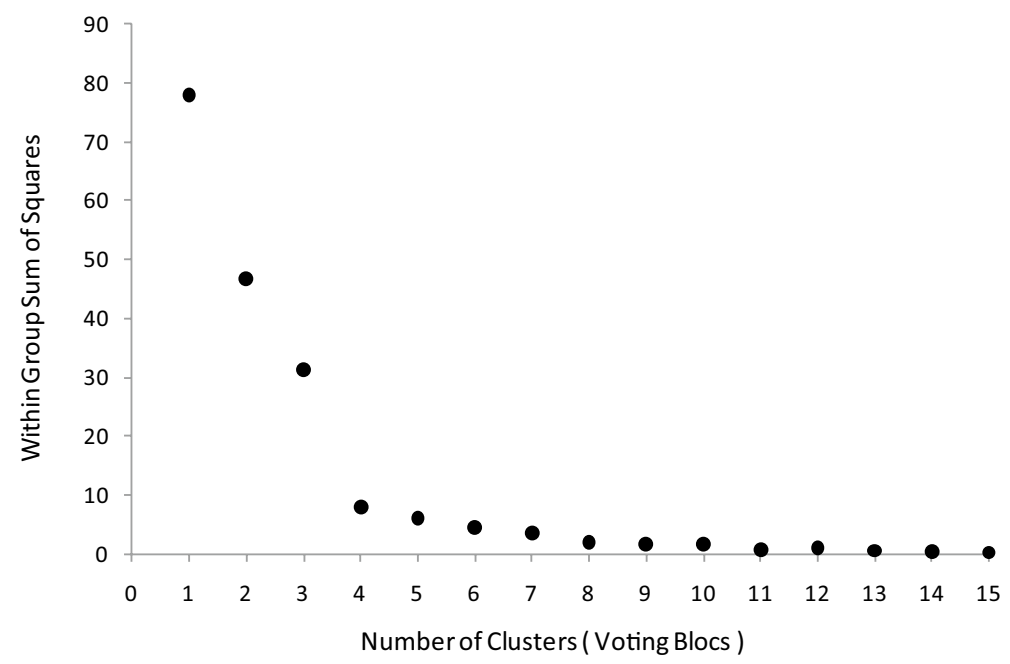

Fig. 2 Optimal number of voting blocs according to k-means

five party groups have headed the governments of the EU's member states, we used the k-means clustering of the left-right positions to place the member states into groups. The main objective of any clustering technique is to obtain groups with a maximum homogeneity within and a maximum heterogeneity between them. The number of clusters has been determined using the usual analysis of the reduction in the within group sum of squared deviations. Figure 2 shows that the optimal number of clusters is between 4 and 5 . These groups of member states are treated as voting blocs in the subsequent analysis. The ideological position of a voting bloc is given by the mean ideological position of its members.

When trying to proceed in a similar manner on the EU integration dimension we find that the variance of the positions of a large majority of EU governments is very low, making the assumption of the same number of distinctive voting blocs along this dimension unreasonable.

The score of a voting bloc then is the average score of its constituent member states (Table 1). Since a member of a voting bloc votes in unison with all other members, their number, as well as their voting and population weights, add to the weight of the bloc. On the level of voting blocs, we need a joint probability distribution on the set of 32 conceivable coalitions between the five voting blocs. To construct a correlation matrix between the affirmative votes of the blocs, we 
Table 1 Composition of voting blocs based on ideology and federalization

Size Weight Population Ideology score Federalization

score

\begin{tabular}{lrrrrr}
\hline Voting blocs-ideology dimension & & & & & \\
1 AT CY & 2 & 14 & 9.3 & 6.9 & 9.8 \\
2 BE DK ES FR GR PT RO SI SK & 9 & 124 & 177.6 & 10.6 & 7.7 \\
3 BG EE IT LT MT NL & 6 & 66 & 89.1 & 12.0 & 7.3 \\
4 DE FI HU IE LU LV PL SE & 8 & 100 & 152.5 & 13.4 & 7.8 \\
5 CZ GB & 2 & 41 & 74.2 & 15.3 & 16.3 \\
Voting blocs-EU federation dimension & & & & & \\
$1 \quad$ DK EE NL & 3 & 24 & 23.7 & 11.4 & 6.5 \\
2 AT IE & 2 & 17 & 13 & 10.4 & 7.4 \\
3 BE BG ES FI FR GR IT LT MT PT RO & 12 & 169 & 246.4 & 11.3 & 7.7 \\
$\quad$ SK & 7 & 90 & 144.5 & 13.0 & 8.0 \\
4 DE HU LU LV PL SE SI & 3 & 45 & 75.1 & 12.2 & 14.9 \\
5 CY CZ GB & & & & & \\
\hline
\end{tabular}

Table 2 Correlations between voting blocs based on ideology and federalization

\begin{tabular}{llllll}
\hline & Bloc 1 & Bloc 2 & Bloc 3 & Bloc 4 & Bloc 5 \\
Bloc 1 & 1 & 0.18 & 0.21 & 0.23 & 0.27 \\
Bloc 2 & & 1 & 0.32 & 0.35 & 0.40 \\
Bloc 3 & & 1 & 0.40 & 0.46 \\
Bloc 4 & & & 1 & 0.51 \\
Bloc 5 & & & & 1 \\
\hline & Bloc 1 & Bloc 2 & Bloc 3 & Bloc 4 & Bloc 5 \\
Bloc 1 & 1 & 0.19 & 0.18 & 0.19 & 0.40 \\
Bloc 2 & & 1 & 0.14 & 0.15 & 0.31 \\
Bloc 3 & & & 1 & 0.14 & 0.30 \\
Bloc 4 & & & & 1 & 0.32 \\
Bloc 5 & & & & & 1 \\
\hline
\end{tabular}

take the cross product between the normalized average scores to compute the offdiagonal elements of the correlation matrix, while the diagonal elements are set to unity. Using this simple procedure, we arrive at the correlation matrices shown in Table 2. The matrices give us a choice of positive correlations that range from close to zero to close to one half. These Pearson product-moment correlation coefficients easily fulfill the consistency conditions discussed in Bahadur (1961) and in Kaniovski and Zaigraev (2011), so that a distribution consistent with correlation matrices shown in Table 2 exists.

Figure 3 shows the joint probability distributions consistent with the correlation matrix based on Ideology Scores for several values of the acceptance probability, or the marginal probability of an affirmative vote by a bloc. The bars show 

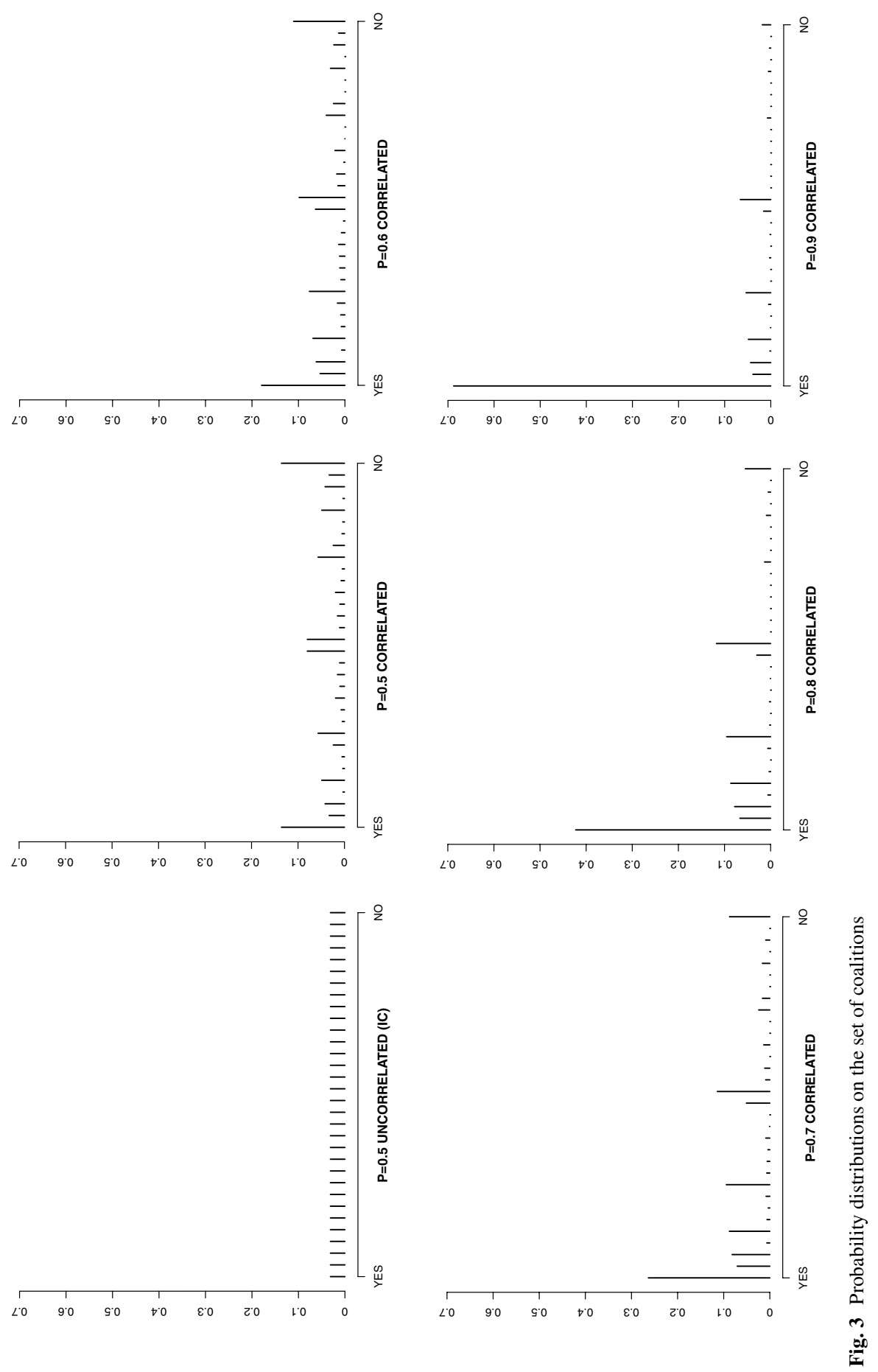
the probabilities of the occurrence of coalitions, sorted in descending order of decimals that their binary vectors represent. The left-most coalition is a grand coalition in favor $(1,1,1,1,1)$ — or a unanimous 'yes' — whereas the right-most coalition is the grand coalition against $(0,0,0,0,0)$, or an unanimous 'no'.

The top left panel shows the distribution in the benchmark case of equally probable and independent (uncorrelated) votes, based on the assumptions of the binomial model of voting, or ICC. Under these assumptions, all coalitions are equally likely to form. Changing the marginal probability of an affirmative vote and introducing positive correlations alters the distribution: increasing the marginal probability increases the probability of occurrence of all divisions with a high proportion of affirmative votes. On the other hand, positive correlation makes all broad coalitions more probable, including those with a high proportion of negative votes, and makes all tight coalitions less probable. Broad coalitions represent divisions with a high degree of consensus or unanimity.

\section{The Capacity of the Council to Act: Nice and Lisbon Treaty Provisions Incorporating Adapted Vote Probabilities}

The EU comprises of twenty-eight member states in total. According to the Nice Treaty-signed on the 26th of February 2001, and in force since February 1st, 2003-QMV in the Council required 260 out of the total of 352 votes to pass a motion. Moreover, a Council decision required support from more than seventeen member states to pass, as well as support from states representing at least $62 \%$ of the EU population (315.9 million as of 2014). These three elements constitute the 'triple majority requirement' of the Nice Treaty. The share of weighted votes needed to attain a qualified majority is $73.9 \%$. Before the Nice Treaty, the decision quota was always roughly $71 \%$ of the total number of votes. This quota has remained relatively stable throughout the history of the EU (Hosli 1993). Under the double-majority rule of the Lisbon Treaty-signed on December 13th, 2007, and in force since November 1st, 2014 - a motion passes if supported by fifteen member states representing at least $65 \%$ of the EU population (331.2 million as of 2014), unless a blocking minority is formed. A blocking minority requires that either the majority condition or the population condition is not met, and the number of member states in opposition is larger than three. The blocking minority clause allows passing a motion despite failing the population condition. These provisions are summarized in Table 3.

Felsenthal and Machover (2001) show, however, that the Nice Treaty's triple majority requirement was in fact superfluous (at least before the 2004 enlargement), as no winning coalition in the EU-15 could satisfy the first two requirements without being composed of a majority of EU member states (see also Algaba et al. 2003). We retain the second and third majority requirements as factors, as their relative effects might increase when the first majority requirement is altered, or when the Council is enlarged. We also account for the effect of blocking minorities in the voting rule of the Lisbon Treaty. Our calculations are thus exact, as they apply all criteria.

What do different voting procedures imply for the relative capacity of the Council to act? Table 4 gives an overview of the proportion of winning coalitions that could 
be formed out of the EU member state total when QMV applied in the Council's decision-making, in the context of the EU-15 following the 1995 enlargement, the EU-25 (since 2004), the EU-27 (since 2007) and the EU-28 (since 2013).

Coleman's original measure of efficiency equals the share of the winning coalitions in the total number of coalitions. Table 4 shows that in the EU-15, this share was 7.8 percent, but under the triple-majority framework of the Nice Treaty, it decreased with the enlargement of the EU to a mere 1.9 percent in the EU-28. In stark contrast, the double-majority rule stipulated by the Lisbon Treaty will significantly increase decision efficiency in the Council. Under the Lisbon Treaty provisions, decision efficiency in the EU-28 will increase to 13.9 percent. The capacity of the EU-28 to act under the Lisbon Treaty would thus even exceed the level enjoyed by the EU-15 after the 1995 enlargement, despite having almost twice as many member states.

The above calculations reflect the effect of the voting rules on the ease of reaching a decision. They are based on the assumption that each member state votes 'yes' independently with a probability of one half (the ICC assumption). Given empirical evidence on actual voting behavior in the Council, however, this assumption may not capture the reality of voting behavior in this institution. Although the number of 'no' votes and abstentions in the Council seems to have increased after the 2004 EU enlargement (Plechanovová 2011), there still seems to be a strong bias to vote with the Council majority rather than to oppose it once a decision has actually been put up to a vote. We can easily enrich the above setting by factoring in the degree of support for the issue on ballot, reflected in the marginal probabilities of an affirmative vote, and the preferences of the member states, based on their ideological positions and reflected in the correlation matrix (see the left panel of Table 2 above).

Calculations in Table 5 demonstrate how predictions regarding decision efficiency change once EU member states are assumed to vote 'yes' with probabilities $0.5,0.6,0.7,0.8$ and 0.9 , respectively. A higher probability of affirmative votes, reflecting a higher homogeneity of preferences among EU states, unambiguously increases the Council's capacity to act in practice. It is important to emphasize that we still maintain the independence of the member states' votes, an assumption that will be relaxed in the subsequent analysis of voting by blocs.

The first row of Table 5 presents the calculations when member states vote 'yes' on proposals with probability 0.5 . Decision efficiency in the EU-28 is 0.02 under the Nice Treaty provisions and 0.14 according to the provisions of the Lisbon Treaty. However, if EU member states have higher probabilities of accepting proposals in formal votes, for instance due to convergence of preferences after a lengthy negotiation process, the Council's capacity to act clearly improves. For example, if the collective probability of voting 'yes' is 0.6 , decision efficiency increases to 0.11 (Nice Treaty) and to 0.37 (Lisbon Treaty) respectively. Gains in the Council's capacity to act are still higher when member states approve proposals with a probability of 0.8. Empirically, at least in the pre-2004 stage, EU member states supported proposals in formal Council voting procedures with a probability of almost 0.98 (Hosli 2007). According to Table 5, even if the probability of affirmative votes in the post-2004 phase were 0.9 , the Council's capacity to act, with these altered assumptions, would still amount to 0.98 (Nice Treaty) and 0.99 (Lisbon Treaty) with the EU of twenty-eight members. 


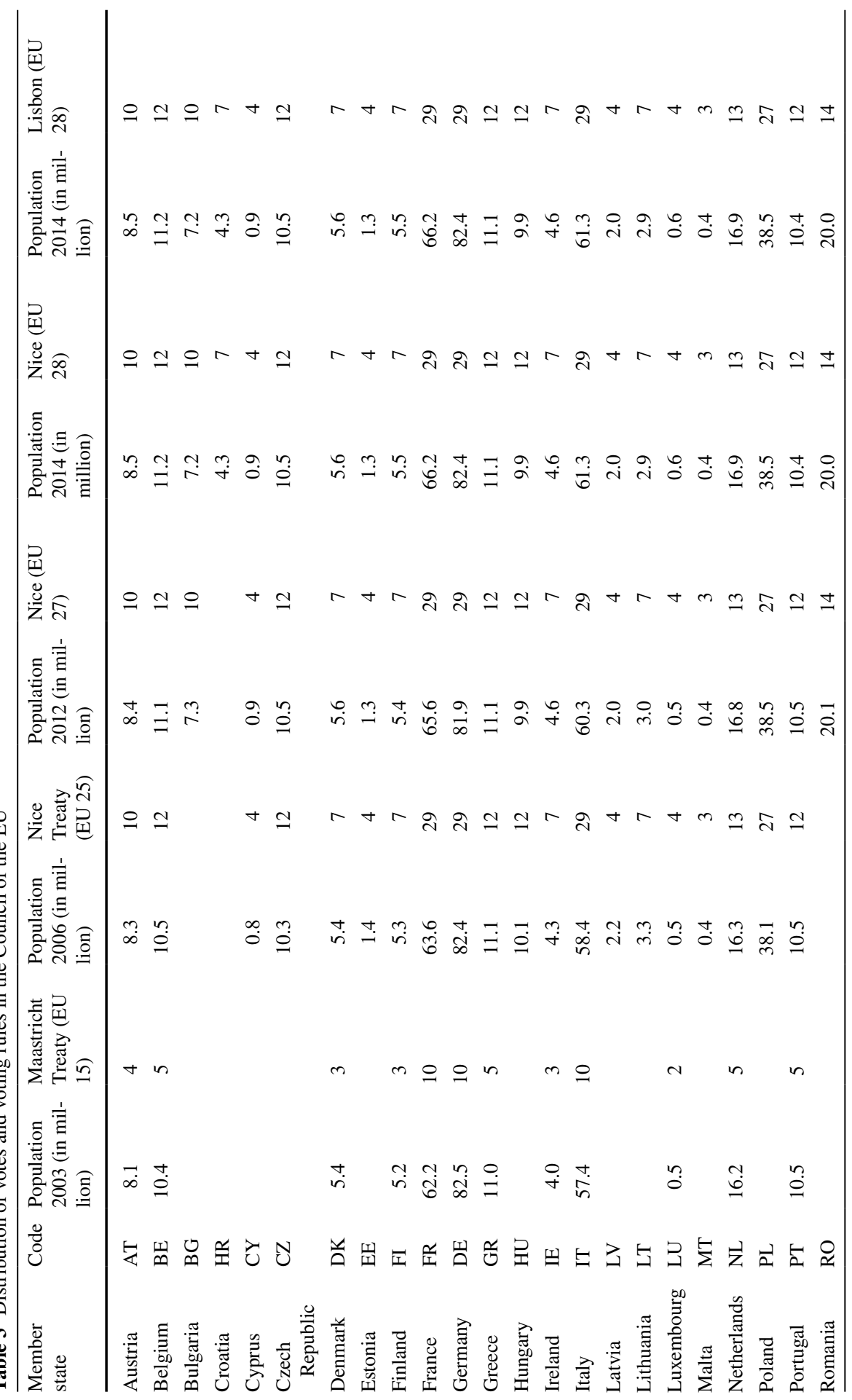




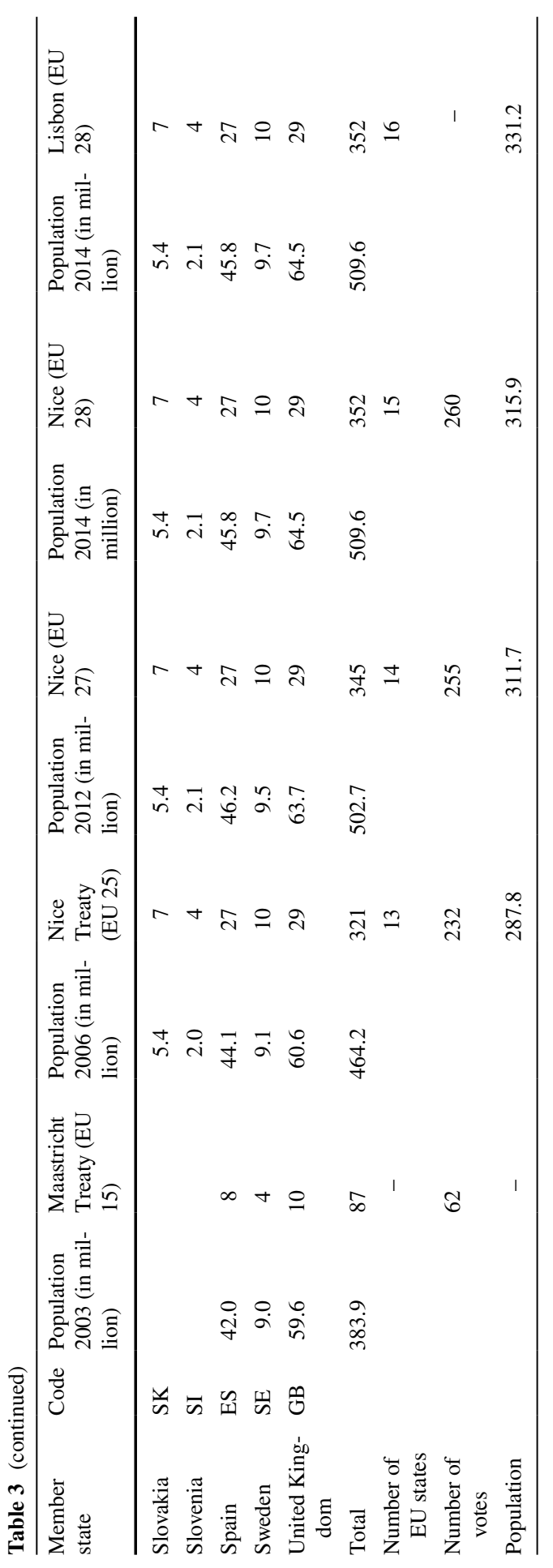


Table 4 Share of winning coalitions in the Council of the EU (Coleman's Index of the capacity of a collectivity to act)

\begin{tabular}{llccc}
\hline Treaty & $\begin{array}{l}\text { Council size } \\
\text { (EU states) }\end{array}$ & $\begin{array}{l}\text { Total number of possible coalitions } \\
\text { (interarrangements) among members }\end{array}$ & $\begin{array}{l}\text { Number of } \\
\text { winning coali- } \\
\text { tions }\end{array}$ & $\begin{array}{l}\text { Share of winning } \\
\text { coalitions in total } \\
(\%)\end{array}$ \\
\hline Maastricht & 15 & 32,768 & 2549 & 7.8 \\
Nice & 25 & $33,554,432$ & $1,203,735$ & 3.6 \\
Nice & 27 & $134,217,728$ & $2,718,738$ & 2.0 \\
Nice & 28 & $268,435,456$ & $5,032,111$ & 1.9 \\
Lisbon & 28 & $268,435,456$ & $37,185,871$ & 13.9 \\
\hline
\end{tabular}

Table 5 Probability of decision with 27 members as a function of $\mathrm{p}$

\begin{tabular}{llllll}
\hline $\begin{array}{l}\text { Probability of } \\
\text { voting 'yes' }\end{array}$ & $\begin{array}{l}\text { Maastricht } \\
\text { EU-15 }\end{array}$ & Nice EU-25 & Nice EU-27 & Nice EU-28 & Lisbon EU-28 \\
\hline 0.5 & 0.08 & 0.04 & 0.02 & 0.02 & 0.14 \\
0.6 & 0.23 & 0.16 & 0.12 & 0.11 & 0.37 \\
0.7 & 0.50 & 0.44 & 0.38 & 0.38 & 0.65 \\
0.8 & 0.80 & 0.79 & 0.75 & 0.76 & 0.88 \\
0.9 & 0.97 & 0.98 & 0.97 & 0.98 & 0.99 \\
\hline
\end{tabular}

Decision efficiency depends on the number of winning coalitions and their probability of occurrence. The interplay of the two factors, however, is complex and cannot be disentangled, especially when number of voters varies. For a fixed number of voters, the decision probability increases with the number of winning coalitions. The share of winning coalitions has decreased continuously till the introduction of the Lisbon voting rules, leading to steady decrease in decision efficiency for moderate values of the probability of a 'yes' vote in Table 5. But for sufficiently high values of this probability, the effect of the changes in the voting rules on decision efficiency abates, as we would expect given that efficiency, being a probability, is bounded by unity from above.

Figure 4 provides a graphical overview of the effects of the decision rules when the probability of affirmative votes increases. Differences in decision efficiency are largest when probabilities of affirmative votes are close to 0.5 . The increase in efficiency associated with an increase in the common probability of an affirmative vote is highest for the EU-28 under the Nice Treaty. This is not surprising, since the efficiency for the EU-28 under the Nice Treaty is lower than for the other three voting systems in the baseline case of $p=0.5$, and yet the efficiency under any voting system must be unity in the limiting case of $p=1$ : in this limiting case, the voting body arrives at a unanimous decision with certainty. This claim is clearly demonstrated in Fig. 4.

According to these calculations, should the Council's 'consensus culture' continue to apply in the future, the probability of reaching decisions in formal Council 


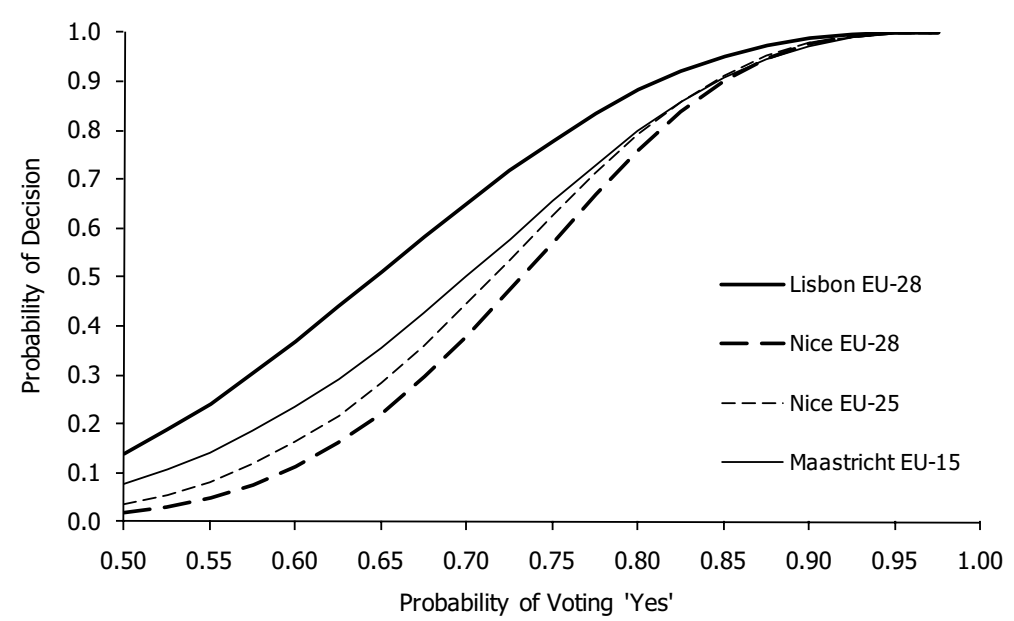

Fig. 4 Probability of decision as a function of $\mathrm{p}$

votes would barely decrease when more members join the EU. However, increased membership will, without a doubt, lengthen the negotiation and bargaining process among the EU states before a proposal is put to a formal vote in the Council. After all, formal Council voting records only capture instances in which the Council has actually resorted to a vote, which is a minority of all cases (Hayes-Renshaw et al. 2006). Decisions made by consensus will hence be the result of long bargaining processes, both among the EU's institutions-notably the Commission, the European Parliament and the Council-and the EU's member states. Voting reflects only 'the tip of the iceberg' in Council decision-making.

Nonetheless, calculations in Table 5 and Fig. 4 may illustrate why there is an apparent contradiction between empirical insights into the speed of EU decisionmaking (Golub 2002, 2007) and respective predictions of Council decision efficiency (Baldwin et al. 2001; Leech 2002; Baldwin and Widgrén 2004; Hosli and Machover 2004) based on the formal voting rules. The assumption of higher probabilities of affirmative votes of EU states in Council voting procedures leads to a prediction of higher probabilities of the Council to act. Whilst these calculations are unable to capture the length and intensity of bargaining prior to the formal Council vote, they may explain why, in reality, in spite of fairly tedious decision rules, decision-making in the Council is still fairly swift, even in an EU of 28 member states.

The preference-based analysis introduces correlations of the affirmative votes in addition to varying marginal probabilities of affirmative votes. For computational simplicity and because of the constraints imposed by the data, the preference-based analysis in this paper is conducted for voting blocs. Since Ideology and Federalization scores are available for the EU 27 (without Croatia who became a member in 2013), we use population weights of 2012 for the 27 EU Member States. We include two variations of the Nice and Lisbon voting rules. The lower requirements ('Nice 14' and 'Lisbon 15') are the usual requirements for the number of EU member states needed to pass a decision on the basis of the Ordinary Legislative Procedure (OLP), 
in which the European Commission submits the initial proposal. These requirements have also been used in all previous computations. The higher requirements ('Nice 18 ' and 'Lisbon 20'), by comparison, correspond to the case when the Council votes on a proposal that was not initiated by the European Commission.

The case of equally probable and independent votes is again included as a benchmark (see the first row of Table 6). Our results hence indicate that there is a major difference between the efficiency calculations for Council decision-making both in case of the Nice and the Lisbon provisions when member state votes are assumed to be correlated. With votes of respective blocs correlated on the basis of shared ideology (left-right positions), the efficiency of the decision-making increases by $14 \%$ points under the Nice rule, assuming equal probability of positive and negative votes being cast. By relaxing this equal probability assumption, the difference gradually declines to $4 \%$ points for the probability of a positive vote of $p=0.9$. Looking for a similar effect of the 'federalization' dimension, we also find this difference, but it is significantly smaller. Assessing the results of the Lisbon rules, we find the highest growth of efficiency at $9 \%$ points under the assumption of independent votes of the blocs, with votes correlated along the left-right dimension. Correlated votes along the 'federalization' dimension again yield a significantly smaller difference compared to the assumption of independent votes. Since the voting blocs are defined by the 'ideology' position of the EU governments, this result was to be expected.

Our findings point to two insights in terms of decision-making rules in the Council of the EU. First, the assumption of uncorrelated voting and equal probability of the votes appears to offer a sound basis for the constitutional principles underlying

Table 6 Probability of decision to act with 5 voting blocs

\begin{tabular}{|c|c|c|c|c|}
\hline $\begin{array}{l}\text { Probability of } \\
\text { voting 'yes' }\end{array}$ & Nice 14 & Nice 18 & Lisbon 15 & Lisbon 20 \\
\hline \multicolumn{5}{|c|}{ Independent votes } \\
\hline 0.5 & 0.19 & 0.19 & 0.31 & 0.16 \\
\hline 0.6 & 0.30 & 0.30 & 0.45 & 0.27 \\
\hline 0.7 & 0.45 & 0.45 & 0.59 & 0.42 \\
\hline 0.8 & 0.61 & 0.61 & 0.74 & 0.59 \\
\hline 0.9 & 0.80 & 0.80 & 0.88 & 0.79 \\
\hline \multicolumn{5}{|c|}{ Correlated votes based on ideology } \\
\hline 0.5 & 0.33 & 0.33 & 0.40 & 0.31 \\
\hline 0.6 & 0.44 & 0.44 & 0.52 & 0.42 \\
\hline 0.7 & 0.56 & 0.56 & 0.66 & 0.54 \\
\hline 0.8 & 0.69 & 0.69 & 0.77 & 0.69 \\
\hline 0.9 & 0.84 & 0.84 & 0.89 & 0.84 \\
\hline \multicolumn{5}{|c|}{ Correlated votes based on federalization } \\
\hline 0.5 & 0.25 & 0.25 & 0.36 & 0.24 \\
\hline 0.6 & 0.37 & 0.37 & 0.49 & 0.34 \\
\hline 0.7 & 0.50 & 0.50 & 0.63 & 0.48 \\
\hline 0.8 & 0.65 & 0.65 & 0.77 & 0.65 \\
\hline 0.9 & 0.82 & 0.82 & 0.88 & 0.82 \\
\hline
\end{tabular}


the voting rules of the Council. As we may see, with the probability of positive votes rising and with correlated votes along any of the two dimensions analyzed here, the efficiency, i.e. the tendency towards a change of the status quo, grows. Second, the ideological positioning of EU governments seems to be a very relevant factor in practice, influencing the efficiency of decision-making in the Council, as correlated votes along this dimension raise the chances of legislation being adopted considerably.

\section{Conclusions}

Coleman's index of the capacity to act is a helpful tool that assesses the decision efficiency of a committee, measuring the share of winning coalitions in all possible coalitions among committee members. By assessing the share of winning coalitions, it implicitly assumes that each committee member casts a positive vote on a bill with a probability of 0.5 , and that the members' votes are independent.

This paper demonstrates how Coleman's index assesses decision efficiency for an institution such as the Council of the EU, in the framework of the EU-15, the EU-25, the EU-27 and EU-28. ${ }^{9}$ It also distinguishes between the effects of the triple majority clause as introduced by the Treaty of Nice and the provisions incorporated into Lisbon Treaty. Respective calculations show that Council decision efficiency has rather strongly decreased since recent rounds of enlargement when assessed with Coleman's index of the capacity of an institution to act, due to both the introduction of the more stringent (triple majority) decision of the Nice Treaty, and an increase in EU membership. By comparison, implementation of the provisions of the Lisbon Treaty will further increase the Council's 'capacity to act'.

It is somewhat puzzling that empirical accounts of Council decision-making do not find an enhanced status quo bias in Council voting behavior after the significant rounds of enlargement, whereas the theoretical assessments would expect a decrease in the frequency with which decisions in this institution can be taken. Calculations presented in this paper provide a possible answer to this puzzle. If the probability of committee members voting in favor of given policy proposals is higher than onehalf, the probability that the committee will reach decisions in formal votes strongly increases. In fact, if this probability is 0.9 , the capacity of the institution to act is close to one, regardless of the voting rule. In other words, if the current 'consensus culture' within the Council of the EU continues to exist in the EU-28 as well as in a possibly further enlarged EU, predictions of the Council's capacity based on homogeneity-adjusted calculations draw a more optimistic picture than traditional assessments based on Coleman's index would. But even the homogeneity-adjusted calculations cannot reflect the decision-making and transaction costs that may occur as a result of possibly intensified bargaining and negotiation processes that precede actual decisions on proposals — usually made by consensus-in the Council of the

\footnotetext{
${ }^{9}$ The effectuation of Brexit will again change decision probability of the Council of the EU as will any other alternations in the composition of the EU's current membership.
} 
EU. Hence, our paper modifies and extends earlier calculations and aims to provide a bridge between 'theoretical' assessments of Council voting efficiency, based on institutional provisions and decision rules, and the actual propensity of coalitions to form, based on ideological connectedness, in the framework of decision-making in the Council of the EU, leading to higher predictability in terms of de facto Council efficiency.

Acknowledgements Madeleine Hosli and Běla Plechanovová have partially worked on this article while being Fellows at the Netherlands Institute of Advanced Studies (NIAS), Theme Group 'Explaining European Union Decision-Making: Insights from the Natural and Social Sciences (EUDINS)'. They thank the NIAS management and colleagues for a valuable research stay at the Institute.

Open Access This article is distributed under the terms of the Creative Commons Attribution 4.0 International License (http://creativecommons.org/licenses/by/4.0/), which permits unrestricted use, distribution, and reproduction in any medium, provided you give appropriate credit to the original author(s) and the source, provide a link to the Creative Commons license, and indicate if changes were made.

\section{References}

Algaba, E., Bilbao, J. M., Fernández, G., Julio, R., \& López, J. J. (2003). Computing power indices in weighted multiple majority games. Mathematical Social Sciences, 46, 63-80.

Bailer, S., Mattila, M., \& Schneider, G. (2015). Money makes the EU go round: The objective foundations of conflict in the Council of Ministers. Journal of Common Market Studies, 53, 437-456.

Bahadur, R. R. (1961). A representation of the joint distribution of responses to $\mathrm{n}$ dichotomous items. In H. Solomon (Ed.), Studies in item analysis and prediction (pp. 158-168), Stanford: Stanford University Press.

Baldwin, R., Berglöf, E., Giavazzi, F., \& Widgrén, M. (2001). Nice try: Should the Treaty of Nice be ratified? London: Centre for Economic Policy Research.

Baldwin, R., Widgrén, M. (2004). Council voting in the Constitutional Treaty-devil in the details, CEPS Policy Brief, No. 53.

Benoit, K., \& Laver, M. (2006). Party policy in modern democracies. London: Routledge.

Braham, M., \& Holler, M. (2005a). The impossibility of a preference-based power index. Journal of Theoretical Politics, 17, 137-157.

Braham, M., \& Holler, M. (2005b). Power and preferences again. A reply to Napel and Widgrén. Journal of Theoretical Politics, 17, 389-395.

Buchanan, J., \& Tullock, G. (1962). The calculus of consent. Ann Arbor: University of Michigan Press.

Coleman, J. S. (1971). Control of collectivities and the power of a collectivity to act. In B. Lieberman (Ed.), Social choice (pp. 27-46). New York: Gordon and Breach.

Coleman, J. S. (1973). The mathematics of collective action. Chicago: Aldine.

Crama, Y., \& Hammer, P. L. (2011). Boolean functions theory, algorithms, and applications. Cambridge: Cambridge University Press.

Crombez, C. (1996). Legislative Procedures in the European Community. British Journal of Political Science, 26, 199-228.

Felsenthal, D. S., \& Machover, M. (1998). The measurement of voting power: Theory and practice, problems and paradoxes. London: Edward Elgar Publishing.

Felsenthal, D. S., \& Machover, M. (2001). The Treaty of Nice and qualified majority voting. Social Choice and Welfare, 18, 431-464.

Felsenthal, D. S., \& Machover, M. (2004). A priori voting power: What is it all about? Political Studies Review, 2, 1-23.

Garrett, G., \& Tsebelis, G. (1996). An institutional critique of intergovernmentalism. International Organization, 50, 269-299. 
Garrett, G., \& Tsebelis, G. (1999). Why resist the temptation to apply power indices to the European Union. Journal of Theoretical Politics, 11, 291-308.

Golub, J. (1998). In the shadow of the vote? Decision making in the European Community 1974-97. International Organization, 53, 733-764.

Golub, J. (2002). Institutional reform and decision-making in the European Union. In M. O. Hosli, A. M. A. van Deemen, \& M. Widgrén (Eds.), Institutional Challenges in the European Union (pp. 134-154). New York: Routledge.

Golub, J. (2007). Survival analysis and European Union decision-making. European Union Politics, 8, $155-179$.

Hagemann, S., \& De Clerck-Sachsse, J. (2007). Decision-making in the enlarged Council of Ministers: Evaluating the facts, CEPS Policy Brief 119. Brussels: Centre for European Policy Studies.

Hagemann, S., \& Høyland, B. (2008). Parties in the Council? Journal of European Public Policy, 15, 1205-1221.

Hayes-Renshaw, F., van Aken, W., \& Wallace, H. (2006). When and why the EU Council of Ministers votes explicitly. Journal of Common Market Studies, 44, 161-194.

Hix, S. (1999). The political system of the European Union. New York: St. Martin's Press.

Hix, S., \& Høyland, B. (2013). Empowerment of the European Parliament. Annual Review of Political Science, 16, 171-189.

Hooghe, L., Marks, G., \& Wilson, C. J. (2002). Does left/right structure party positions on European integration? Comparative Political Studies, 35, 965-989.

Hosli, M. O. (1993). Admission of European Free Trade Association States to the European Community: Effects on voting power in the European Community Council of Ministers. International Organization, 47, 629-643.

Hosli, M.O. (2007). Explaining voting behavior in the Council of the European Union. Paper presented at the First World Meeting of the Public Choice Societies, Amsterdam, March 29-April 1.

Hosli, M. O., \& Machover, M. (2004). The Nice Treaty and voting rules in the Council: A reply to Moberg (2002). Journal of Common Market Studies, 42, 497-521.

Hubschmid, C., \& Moser, P. (1997). The co-operation procedure in the EU: Why was the European Parliament influential in the decision on car emissions standards? Journal of Common Market Studies, $35,225-242$.

Kaniovski, S. (2008). The exact bias of the Banzhaf measure of power when votes are neither equiprobable nor independent. Social Choice and Welfare, 31, 281-300.

Kaniovski, S., \& Das, S. (2015). Measuring voting power in games with correlated votes using Bahadur's parametrisation. Social Choice and Welfare, 44, 349-367.

Kaniovski, S., \& Zaigraev, A. (2011). Optimal jury design for homogeneous juries with correlated votes. Theory and Decision, 71, 439-459.

Kilgour, D. M., \& Levesque, T. (1984). The Canadian constitutional amending formula: Bargaining in the past and the future. Public Choice, 44, 457-480.

König, T., \& Bräuninger, T. (1997). The institutional politics of enlargement: Diverging goals for a reform of EU legislation. Paper presented at the IPSA Seminar to the Intergovernmental Conference, Brussels, July 10-12.

König, T., \& Bräuninger, T. (1998). The inclusiveness of European decision rules. Journal of Theoretical Politics, 10, 125-142.

König, T., \& Bräuninger, T. (2002). From an ever-growing towards an ever-slower Union? In M. O. Hosli, A. M. A. van Deemen \& M. Widgrén (Eds.), Institutional Challenges in the European Union (pp. 155-172). London and New York: Routledge.

Kurz, S., \& Napel, S. (2016). Dimension of the Lisbon voting rules in the EU Council: A challenge and new world record. Optimization Letters, 10, 1245-1256.

Lane, J.-E., \& Maeland, R. (1995). Voting power under the EU constitution. Journal of Theoretical Politics, 7, 223-230.

Laruelle, A. (1997). The EU decision-making procedures: some insight from non-cooperative game theory, Discussion Paper 9727, Institut de recherches économiques et sociales (IRES). Belgium: Louvain-la-Neuve.

Leech, D. (2002). Designing the voting system for the Council of the European Union. Public Choice, $113,437-464$.

Mattila, M. (2004). Contested decisions: Empirical analysis of voting in the European Union Council of Ministers. European Journal of Political Research, 43, 29-50. 
McElroy, G., \& Benoit, K. (2012). Policy positioning in the European Parliament. European Union Politics, 13, 150-167.

Moser, P. (1996). The European Parliament as a conditional agenda setter: What are the conditions? A critique of Tsebelis. (1994). American Political Science Review, 90, 834-838.

Moser, P. (1997). A theory of the conditional influence of the European Parliament in the cooperation procedure. Public Choice, 91, 333-350.

Napel, S., \& Widgrén, M. (2004). Power measurement as sensitivity analysis: A unified approach. Journal of Theoretical Politics, 16, 517-538.

Napel, S., \& Widgrén, M. (2005). The possibility of a preference-based power index. Journal of Theoretical Politics, 17, 377-387.

Napel, S., \& Widgrén, M. (2006). The inter-institutional distribution of power in EU codecision. Social Choice and Welfare, 27, 129-154.

Naurin, D., \& Lindahl, R. (2008) East-North-South: Coalition-building in the Council before and after enlargement. In D. Naurin, \& H. Wallace (Eds.), Unveiling the Council of the European Union (pp. 64-78). London: Palgrave Macmillan.

Peters, T. (1996). Decision making after the EU intergovernmental conference. European Law Journal 2.

Plechanovová, B. (2004). The draft constitution and the decision-making rule for the Council of Ministers of the EU: Looking for an alternative solution. European Integration online Papers (EIoP), 8.

Plechanovová, B. (2011). The EU Council enlarged: North-south-east or core-periphery? European Union Politics, 12, 87-106.

Schulz, H., \& König, T. (2000). Institutional reform and decision-making: Efficiency in the European Union. American Journal of Political Science, 44, 653-666.

Selck, T. J. (2005). Explaining the absence of inertia in European Union legislative decision-making. Journal of Common Market Studies, 43, 1055-1070.

Sherrington, P. (2000). The Council of Ministers: Political authority in the European Union. London and New York: Pinter.

Sloot, T., \& Verschuren, P. (1990). Decision-making speed in the European Community. Journal of Common Market Studies, 29, 75-85.

Steunenberg, B. (1994). Decision-making under different institutional arrangements: Legislation by the European Community. Journal of Theoretical and Institutional Economics, 150, 642-669.

Thomson, R., \& Hosli, M. O. (2006). Who has power in the EU? The Commission, Council and Parliament in legislative decision-making. Journal of Common Market Studies, 44, 391-417.

Tsebelis, G. (1994). The power of the European Parliament as a conditional agenda setter. American Political Science Review, 88, 128-142.

Tsebelis, G. (1995). Decision making in political systems: Veto players in presidentialism, parliamentarism, multicameralism, and multipartyism. British Journal of Political Science, 25, 289-326. 